\title{
Narrative Inquiry: Attending to the Art of Discourse
}

\author{
Carl Leggo \\ University of British Columbia
}

Storytelling is an attempt to deal with and at least partly contain the terrifyingly

haphazard quality of life. (Fulford, 1999, 14)

Every interpretation is a political move. (Marshall, 1992, 192)

Here I am, at the border between story and history, personal desire and a shared reality over which I have no more power than I do over my dreams. (Keefer, 1998, 163)

At least once a year, I teach a graduate course titled Narrative Inquiry. Students from many different disciplines, including education, health, nursing, creative writing, and psychology, register for the course with the anticipation that they will learn how to do narrative inquiry. At the beginning of the course I always inform students that they will not likely learn how to do narrative inquiry in the narrative inquiry course. Instead they will interrogate the strategies, purposes, practices, and challenges of narrative inquiry, and they will learn how complicated, even messy, the whole business of narrative inquiry really is. I organize the course around an investigation of three principal dynamics involved in narrative inquiry: story, interpretation, and discourse. I explain that story is what happened. Therefore, story can be researched by asking the journalist's questions: who? what? when? where? why? how? Then, interpretation addresses the basic question of so what. In other words, what is the significance of the story? Finally, discourse is all about how we tell the story. Discourse refers to the rhetoric of storytelling, the art and science of shaping and constructing a story for communicating to others. (While the distinction between story as what happened and discourse as how the Language and Literacy 
story is told is discussed widely in the scholarly literature of narratology, or the study of narrative, I am especially indebted to Chatman [1978] since I first met the explanation I use in his Story and Discourse: Narrative Structure in Fiction and Film.) I also explain that in social science research the question of interpretation is often cast as the most important question because so much social science research is about conclusions and implications. The social scientist is always asking: What does all this mean for practice and policy? Nevertheless, while certainly paying attention to story and interpretation, I focus the narrative inquiry course on questions, issues, strategies, and processes related to discourse. I invite students to consider matters related to story and interpretation, but I encourage them especially to attend to the art of discourse.

Story: what happened?

We are born into stories, including the stories of family, community, and nation. Cobley (2001) observes that "wherever there are humans there appear to be stories" (2), and Fulford (1999) notes that "stories are how we explain, how we teach, how we entertain ourselves, and how we often do all three at once" (9). I heartily agree with Baldwin (2005) who claims that "story is loose in the world, and the people of the world are communicating as never before" (33). She notes that "an estimated fifteen million blank-book journals sell every year in the United States" (32). And we only need to consider the exponential growth of e-mail, blogging, personal websites, MSN Messenger, YouTube, and Facebook, in order to understand Baldwin's observation that "we have created a web of technology that frees story as never before" (90). According to Baldwin, "with our determination to write ... we are laying a new foundation for the future, laying out a grid of millions of stories. Not just those of the famous people or the 
powerful people, but the stories of ordinary people" (44). We are awash in stories. We are epistemologically and ontologically engaged in using stories as an integral way to sort who we are as people in relation to other people. We are all creatively engaged in processes of identity formation and transformation by attending to stories. Everybody lives stories, all the time, and everybody attends to the stories of others. And not only do we tell stories to ourselves and one another, but there are many stories that we have, at best, only limited access to, including the stories of dreams, fantasy, imagination, and memory. We hear and witness stories in our homes, in schools, in public spaces, in places of worship; we attend to stories on television and in movies; we understand the past in stories, and we seek to know the future in stories.

But, even though stories are ubiquitous in our lives, most of us have little confidence about our abilities as story-tellers. Where does this lack of confidence come from? Recently I was commuting with my daughter from work to home, and I was telling her stories in a lackluster kind of way, filling the air with chatter, feeling that silence was inappropriate, when my daughter teased me, "You are telling me stories we both heard on the radio this morning when we commuted to work." Then she laughed with a mock judgement, "You are story-poor." And I was struck by how frequently I tell the stories I hear on the radio or TV or read in the newspaper, as if these stories have been sanctioned with an appropriate value by their public transmission, and how often I avoid telling the stories of my own life because they seem not adequately important.

One of the main sources behind a lack of confidence in telling our stories derives from our school experiences with composing stories. In school I was taught that good stories were shaped by an effective balance of many elements. The process of making a 
story was like baking a cake. The successful story-writer mixed various elements together in a way that resembled the stories in class textbooks. I spent years in school trying to imitate the kinds of stories that I read or watched on TV. I wrote stories with predictable plots, seasoned with suspense like spices, and fast action, and exciting adventures. I never wrote about my daily life, never wrote about the events, experiences, and emotions of growing up in a working-class neighbourhood in a working-class town. I never wrote about anything or anybody that was personally meaningful. As far as I was concerned, the ordinary stories of my family and neighbourhood experiences, lived daily, lived year after year, were not sanctioned or sufficiently significant for writing stories in school. I almost agree with Cobley's (2001) observation that "catching the bus, going out with friends, performing mundane tasks at work, watching football—none of these come to fruition as stories unless we choose to impose some kind of narrative form on them" (8). But, where I disagree with Cobley is simply that I think the mundane events of our lives are already stories, but they are only invested with significance in the ways they are told. Just as an artist represents a still image of the ocean rolling onto a beach, the writer holds a moment, or part of a moment, in order to draw attention to it. In this way the artist and the writer present to us images that are emblematic of the billions of moments that are given little attention.

From the perspective of the novelist, Amis (2000) claims:

the trouble with life ... is its amorphousness, its ridiculous fluidity. Look at it: thinly plotted, largely themeless, sentimental and ineluctably trite. The dialogue is poor, or at least violently uneven. The twists are either predictable or sensationalist. And it's always the same beginning; and the same ending. (7) 
But I disagree with Amis, and I suspect that he is simply making an extreme point for the sake of emphasis. There is nothing any more ridiculous about the fluidity of life than there is anything ridiculous about the creative abundance of the universe. I could complain that there is something ridiculous about all the stars in the night sky, or all the species of plants, animals, fish, and insects in the earth! Life is abundant, and narrative inquiry is a way of focusing on some particulars of that abundance. According to Fulford (1999), the popularity of narrative is due to "the ability to bestow meaning on otherwise disorganized events" (113). I am not sure that narrative bestows meaning as much as it recognizes some of the possibilities of meaning that lie always in the seemingly tangled messiness of lived experience.

What writers, story-tellers, and artists of all kinds attempt to do is frame fragments of experience in order to remind us that there is significance in the moment, in the particular, in the mundane. But that significance is highlighted in stories that are told and written in energetic and engaging and evocative ways. I am not interested in hearing what a friend ate for breakfast unless the story is told in a way that is full of interest. We all know friends, family, co-workers, and neighbours who are boring. Why are they boring? Perhaps because they have told their stories, the same stories in the same ways, many times already, or perhaps because they tell the stories with no interest in hearing others' stories, without any commitment to dialogue and reciprocity, or perhaps because they have no awareness of their audience and tell the stories only because they enjoy hogging the spotlight. So, in the Narrative Inquiry course, I remind participants that we all live stories all the time, and I encourage them to attend to their stories and the stories 
of others, and to celebrate the inexhaustible ubiquity of stories. Then, we turn to the second principal dynamic of narrative inquiry: interpretation.

Interpretation: so what?

In the same way that I promote the ubiquity of stories, I also challenge any notion that in writing stories about experience we can contain the multiplicity of interpretations. Instead, using a reader response orientation, I recommend that we present our representations, and invite readers to make sense out of our stories. In other words, let readers contribute to making meaning out of the stories, as they inevitably will anyway. Instead of trying to close down understanding, we should be opening up possibilities for wide-ranging connections, questions, and insights.

Several years ago, I was invited to present a workshop at a conference of oncologists. I had no experience with oncologists, and I didn't really know what to expect, but I anticipated that I would meet a group of scientists in lab coats. I decided I should prepare a straightforward strategy for interpreting narratives, a rubric even, the kind of strategy that I assumed might appeal to objective, scientific, rigorous people who need to get a job done, and need to get it done quickly. In fact, at the conference I met a diverse gathering of social workers, therapists, doctors, and nurses. I presented my rubric which I titled RITES because I hoped a rubric with an acronymic title would appeal to the sense of order and process I assumed my audience would hold fast to. I presented RITES as a heuristic method for interpreting narratives. The several steps include:

Step one: Read

The researcher reads the whole narrative to gain a general sense of the story.

Step two: Interrogate 
The researcher asks some basic questions: who? what? where? when? why? how? so what?

Step three: Thematize

The researcher reads the narrative again with a focus on a theme, and spells out the parts of the story which relate to the theme.

Step four: Expand

The researcher expands on the theme by reflectively and imaginatively drawing connections and proposing possible meanings.

Step five: Summarize

The researcher summarizes the theme in a general statement or two in order to indicate clearly what is learned from the narrative.

The oncologists were generous in responding to the rubric, as are some of my graduate students who assure me that the rubric is useful. But I continue to be concerned that this rubric simplifies complex processes, and promotes the understanding of interpretation as formulaic like a paint-by-numbers canvas. I agree with Cobley's (2001) observation that "even the most 'simple' of stories is embedded in a network of relations that are sometimes astounding in their complexity" (2). In order to emphasize his point, and I think the point needs emphasizing, Cobley adds, with echoic parallelism, that "the most familiar, most primitive, most ancient and seemingly most straightforward of stories reveals depths that we might hitherto have failed to anticipate" (2). Fulford (1999) understands correctly that "there is no such thing as a value-free story" (6) because "stories inevitably demand ethical understanding. There is no such thing as just a story. A story is always charged with meaning, otherwise it is not a story, merely a sequence of 
events" (6). Above all, narrative inquiry is an invitation to enter into a lively and productive discussion of how stories are always steeped in gaps and silence and surprises.

When we read or hear or view a story, we always enter into a co-production with the text and the author in order to help produce the meaning. In fact, what is interesting is the way that our reading is always motivated, facilitated, and constrained by our personal experiences and ideology, as well as the cultural expectations and ideologies that shape our sense of identity and our sense of location in the world. As Freire (1993) says, "every reading of the word is preceded by a reading of the world" (58). We always bring our cultural, social, economic, political, and spiritual views and experiences to bear on every reading of verbal and visual texts. And we are always informed and shaped by the views and experiences of others, too. So, interpretation needs to be entered into with care and openness and critique. For a long time, in my own writing I was reluctant to criticize the views of other writers because I suspected that if I had the opportunity to talk with them, they would tell me simply that I had misunderstood them. I am concerned about misinterpretation because I see the hurt and harm that it causes so many people so much of the time. We need to be able to tell stories with a tentativeness, a sense of being in process, an acknowledgement that any interpretation is temporary. Again, I appreciate Fulford's (1999) cautionary observation:

stories, however valuable, may be puzzling as well as engaging.... Stories ostensibly begin in order to explain something, or to make an event clear. They turn an incident this way and that, throw several kinds of light on it, surround it with a certain mood — and then put it back in its place, still unexplained. (8) 
So, I continue to provide the rubric RITES to graduate scholars, but always with the cautionary advice to approach every text with an eagerness to engage with the text's openness and multiplicity and mystery. Above all, I want to avoid simplistic ways of telling, writing, interpreting, communicating, and understanding stories. Instead, I am eager to promote the possibilities and complexities of the third dynamic of narrative inquiry: discourse, or how the story is crafted and constructed.

Discourse: how do we tell the story?

We must keep in mind that there are really only a few stories. Essentially, the entire population of billions of people on the planet Earth, with all our distinct cultural, economic, epistemological, ethnic, geographical, historical, ideological, political, sociological, and spiritual differences, still live the same basic stories. We all share experiences of desire, fear, relationship, birth and death, pain and fear, joy and sorrow. So, we are not going to learn a great deal that is startlingly new from listening to another person's story. To paraphrase the ancient Hebrew preacher whose wisdom is recorded in the Book of Ecclesiastes, there is hardly anything new under the sun, moon, or stars. The real purpose of telling our stories is to tell them in ways that open up new possibilities for understanding and wisdom and transformation. So, our stories need to be told in creative ways that hold our attention, that call out to us, that surprise us. What really makes a story interesting and valuable, then, is the way it is told. I appreciate Clandinin and Connelly's (2000) notion of narrative as both phenomenon and method. They explain that they "have been pursuing this work under the heading of narrative inquiry with a rough sense of narrative as both phenomena under study and method of study" (4). In a related way, I am claiming that the story or experience is the phenomenon, and the discourse is 
the method. Basically I am calling for narrative researchers to pay more attention to the ways they write or compose or construct the narratives.

Any discussion of discourse needs to begin with a careful consideration of the elements of narrative. I invite my students to brainstorm all the elements of narrative, and we are always surprised at how many elements comprise any narrative enterprise. For example, the elements of narrative writing include: action, allusions, anticlimax, atmosphere, balance, bathos, borders, change, characters, chronology, cliffhangers, climax, closure, coherence, communication, conciseness, conflict, constraint, continuity, conventions, denouément, desire, details, detours, dialogue, distance, drama, emotion, emphasis, endings, events, exposition, fantasy, fiction, flashbacks, flow, foreshadowing, games, gaps, glosses, heart, humour, imagery, intrigue, irony, jeopardy, jokes, journeys, joy, keenness, keys, kinaesthesia, language, limits, linearity, memory, metaphor, mimesis, mood, motifs, movement, narrator, naturalism, order, organization, pace, parody, plants, plot, point of view, precision, problem, quests, questions, quotidian, reality, resolution, rhythm, satire, scenes, secrets, selection, series, setting, signs, silence, structure, summary, surprises, suspense, symbols, tension, theme, time, tone, understanding, undertone, unity, verisimilitude, vigour, vitality, voice, wisdom, wit, wonder, words, yearning, zeal, and zigzags. With so many elements to consider when composing narratives, I always advise students to attend especially to voice, and to construct their stories with a resounding sense of voice.

The pressing challenge with advising a person about the craft of story-making is that much of the process defies guidelines and rules. Instead, the process is idiosyncratic, always changing, culturally conditioned, creatively organic. For example, a basic rule 
that is frequently promoted in story-writing workshops is: show, don't tell. Literary critics often use the Greek words mimesis and deigesis to represent telling and showing. A storywriter should not tell the reader what to feel or think or how to respond. Instead, a good story-writer constructs characters and events so readers can enter vicariously into a sense of lived experience. But a basic rule like, show, don't tell, is not a cardinal rule that all stories must faithfully follow. In fact, there are no rules of story-making that cannot be contravened all the time. Effective story-telling often depends on the contravention of conventions. And certainly how stories are told in one cultural community will differ from the ways stories are told in another cultural community. So, writers and readers need an openness to the possibilities of what a story is and can be.

This is particularly clear in what is now called postmodern fiction where the act of narrating is foregrounded. For example, as McHale (1987) explains, the artist in postmodern fiction is "no longer content with invisibly exercising his freedom to create worlds" (30). Instead, "the artist now makes his freedom visible by thrusting himself into the foreground of his work" (30). In a related way, Cobley (2001) refers to "the 'rupturing' effect in fiction, an effect which consists of the narrating agency revealing itself" (172). A memorable instance of this rupturing effect occurs in Woody Allen's film Annie Hall (1977). The character played by Woody Allen is standing in a line to purchase a ticket for a movie, while another person nearby is discussing the views of Marshall McLuhan. Woody Allen's character complains that the man doesn't understand McLuhan correctly, and an argument follows. To make his point, Woody Allen's character steps out of the line and addresses Marshall McLuhan (the real McLuhan who just happens to be standing behind a pillar a few feet away). Woody Allen's character asks, Is that what 
you meant? McLuhan responds, No. From this kind of postmodern perspective, Woody Allen continues to disrupt the conventions of seemingly transparent narration in films like The Purple Rose of Cairo (1985) where a matinee idol walks out of his movie and enters the world of a romantic woman performed by Mia Farrow. The idol soon proves to be much less romantic in the real world of Mia Farrow's character than he was in the movie that she enjoyed watching as an escape from her humdrum world.

There is a growing body of fiction and film narratives that are well-described by the phrase postmodernist. One of my favourite stories is David Arnason's (1992) “A Girl's Story" which plays innovatively with the conventions of story-writing, including stereotypical traits for characters, the prevalence of symbols, and the traditions of romance. In "A Girl's Story" the author/narrator is always breaking into the narration with comments on the process, including decision-making, difficulties, and frustrations. Fulford (1999) complains about "distortions of storytelling" (95). Fulford is concerned that postmodern discursive practices disrupt the straight-forward, realistic narrative. Fulford assumes that there is a correct way to tell a narrative, and that postmodern disruptions of traditional ways of constructing a narrative must be avoided. The authors of postmodern narratives promote the view that behind every story is another story, and that to tell one story is to silence numerous others. Postmodernists are not seeking to undermine the concept, practice, and significance of narrative. Instead, postmodernists are eager to expand the possibilities of narrative.

There is no single way to write narratively. Basic advice claims that a story should show, not tell, but there are really no rules for narrative writing. Most students in secondary school writing classes learn that a story plotline is linear, and involves a 
progression from exposition to critical incident to rising action to the climax followed by the falling action or denouément. As a school teacher I taught this understanding of the plotline many times. This notion of the plotline can be traced to Aristotle's Poetics (written in $350 \mathrm{BCE}$ ). Not only is this the prevalent, and often only, notion of plot presented in school classrooms, but the linear plotline is also a staple of TV dramas and situation comedies, and many Hollywood movies.

There are many ways to tell a story. For example, like Ukrainian stacking dolls or Chinese boxes, a narrative structure can present a story inside a story inside a story. Or stories can be told as circles, or collage, or parallel accounts, or poetry, or photography. Stories can be narrated from multiple perspectives. Stories can be represented in a line that twists and turns, here and there, like a child exploring the hallways of a school on the way to the washroom. A story can be a series of hills and valleys like a heart monitor's report. The possibilities are numerous. A story can be like a series of buoys floating in the ocean, connected to a rope, a net perhaps, anchored to the bottom of the ocean, seemingly disparate but indeed connected. A story can be a series of postcards or letters, or a documentary, or a braid. A story can be a hypertext with numerous paths.

Consider Robert Altman's film Short Cuts (1993) based on the short stories of Raymond Carver in which the characters live their distinct experiences in the specific geographic locale of Southern California but almost never interact. Or consider a somewhat similar film like Paul Thomas Anderson's Magnolia (1999) with its multiple separate stories that are all connected by a common experience of sadness and misery, with ultimately a hint of hope, stories that are only tangentially connected through the kind of daily incidental circumstances that lead to strangers crossing paths, even if only 
briefly. Or consider Peter Howitt's Sliding Doors (1998) which presents parallel stories with a "what if" premise. Or consider the episode of Seinfeld which narrates the events of a wedding by beginning at the end of the episode and telling the story backwards. Or consider a novel told in poetry like Creech's Love That Dog (2001). There are countless examples of innovative approaches to shaping narration in film, television, drama, and writing. In fact, the linear plot line might be a useful way to represent some stories, but it is, at best, only one way. It is not a truer way or a more useful way. Just one way.

In this regard, I find very useful the perspective of Walden (2003), a philosopher and photographer, who distinguishes between place and space:

The world of place is the world of subjective human experience and significance. The world of space is the objective world of points in space-time that are meaningless to humans, abstractions that can be represented in mathematics or physical geography. Space ordinarily comes first, developing aspects of place with the onset of human habitation. A rock takes on significance by becoming the rock that took the bottom out of Gus's boat. A tree takes on meaning by becoming the one in which the children play. (18)

This distinction represents an intriguing way to understand how amorphous experience can be rendered in narrative inquiry in order to evoke the significance of events for the people who live the experiences. Walden adds that "photography is capable of depicting this more intangible quality, depending on not only what is photographed, but also how it is photographed" (19). In a similar way, I think that narrative writing can most effectively conjure the significance of lived experience by attending to how the stories are told. 
Cobley (2001) echoes Walton's perspective with his understanding of time. He writes about:

two types of temporality: 'objective' time and 'subjective' time. 'Objective' time co-exists with the universe, it is embodied in the movements of the heavenly bodies, it always has been and there is nothing that we can do about it....

'Subjective' time is temporal passage as it is experienced by humans going about their lives. (17)

Narrative inquiry is an ongoing process of understanding how we invest space and chronology with significance. In constructing stories to explain and account for our lived experiences, we transpose space into place, and objective time into subjective time. In a related way, Clandinin and Connelly (2000) spell out "a metaphorical three-dimensional narrative inquiry space, with temporality along one dimension, the personal and the social along a second dimension, and place along a third" (50).

Cobley (2001) explains that "at their simplest, all narratives are the movement from a beginning point to a finishing point. Narrative is just a sequence which starts and moves inexorably to its end" (9). But is this observation sufficient for understanding narrative as experienced by everybody all the time? I hardly think so. Cobley's notion of narrative as "the movement from a beginning point to a finishing point" is dependent on the conception of a linear plot line. I think a more useful way of conceptualizing narrative is in terms of a rhizome where there is no centre from which everything grows in a specific direction. The rhizome goes in many directions, without a centre. In the same way, I find very useful the whole notion of hypertext for representing the storied life. In a hypertext, there are numerous paths and links, numerous ways of moving along and 
amidst the possibilities. Traditional narrative is bound up with an understanding of time. A person is born, grows up, grows older and older, and dies. Typically. So, life is perceived as linear. Robert Frost's familiar poem “The Road Not Taken" reminds us that our lives are substantially shaped by a youthful and necessary decision to follow one path and not another, but really we make choices to follow one path and not another all the time. It is not simply that when we are in our early twenties we decide to be a teacher instead of an astronomer or taxidermist, and that our lives are then prescribed for us. We make many choices throughout our lives, choose many paths, and exclude many paths. This is the way of living, and this is the way of narrative, too. We are always engaged in an ongoing process of selection and exclusion. Cobley notes that "narrative selects some events and omits others" (7). Perhaps the important lesson to be learned from this process is that we must be cautious that we don't pretend that our life script is somehow predetermined, written for us, clearly etched like railway tracks that we are racing along.

From a Foucauldian perspective on discourse Mills (1997) notes that subjects engage "in their own constitution, acquiescing with or contesting the roles to which they are assigned" (45-46). For Mills, "there is no intrinsic order to the world itself other than the ordering which we impose on it through our linguistic description of it" (52). Therefore, "the only way we have to apprehend reality is through discourse and discursive structures" (54). I find this view very helpful. It is certainly closely related to J. Bruner's constructivism, M. van Manen's phenomenology, S. Tyler's postmodern ethnography, C. Ellis' autoethnography, as well as Clandinin and Connelly's narrative inquiry. I find Mills' view useful for understanding more clearly the ways that writing shapes identity, memory, and hopes. 
And there are many different kinds of narrative genre in which to tell our stories, including: allegory, anecdote, art, autobiography, biography, blog, cartoon, clothing, confession, curriculum vitae, dance, diary, drama, dream, embodiment, epic, fable, fantasy, fiction, film, genealogy, geography, history, hypertext, illustration, imagination, irony, joke, journal, kudo, legend, lie, life writing, lyric, memoir, metafiction, myth, narrative poem, newsletter, newspaper, novel, ode, parable, parody, photography, postcard story, poster, puzzle, questions, quilt, quiz, quotation, reminiscence, report, scrapbook, short story, sketch, song, tale, testimony, translation, uniform, video, vignette, waxworks, weaving, website, xerography, X ray, yarn, yearbook, zip code, and zodiac.

In the narrative inquiry course that I teach, for one assignment students compose a poster. Each student selects some aspect of their teaching/researching/writing/living experiences, and designs a poster (using a sheet of Bristol board). For many of them, this experience is the first time since elementary school that they have represented an aspect of their experience in a visual way. The process is often scary, as innovative research often is, but the final exhibition and explanation of the posters is always a celebration of risk-taking research that is both personal and pedagogical. Also, in the course, students engage in all kinds of writing (including autobiography, drama, poetry, fiction, scripts), as well as photography, art, dance, quilting, weaving, paper maché, video presentations, and web pages. Above all, the students transcend straightforward ways of telling stories in order to experiment with the discursive possibilities of story-telling, thereby seeking complex and artful and richly nuanced representations of lived experience.

As I draw this essay to a close, consider my poem titled "My Problem," which narrates a common adolescent experience, remembered many years later. What always 
intrigues me about narrative inquiry, whether it is poetic, fictional, filmic, or scholarly, is the way that a story always opens up more questions than it provides answers. As Fulford (1999) understands,

stories, however valuable, may be puzzling as well as engaging.... Stories ostensibly begin in order to explain something, or to make an event clear. They turn an incident this way and that, throw several kinds of light on it, surround it with a certain mood - and then put it back in its place, still unexplained. (8) I invite you to read the following poem, and then attend to my recent ruminations on the poem.

\section{MY PROBLEM}

After climbing Valley Road

one late spring evening

(summer anywhere else in Canada)

I sat with Cassandra

(seduced by my sixteen-year-old

imagination I had written

her the heroine

of my romantic stories)

on the back steps of her parents' house

looking for God hiding among the stars

and explaining why if I were American, not Canadian, I would refuse

to fight in the Vietnam War, 
and Cassandra said, I don't

want to go out with you anymore,

your problem is you want

to change the world.

I'm glad she told me.

I didn't even know

I had a problem.

Even at fifty-four years old, I can still recall the incident narrated in "My

Problem," and what I remember most right now is the sense of grief and agony I felt that summer evening when my girlfriend broke up with me. Of course, I have long ago

relinquished the sadness and hurt, but the story still holds it, almost like a trust account where deposits can be secured until the time when you want to retrieve them. In writing the poem "My Problem" when I was in my forties, I chose to tell the story with a wry and witty voice because that is the kind of mature voice that I like to use in public contexts, but, of course, that sardonic tone was no part of the initiating experience which I knew with all the discomfort and shock that most people feel when they are being dumped. But what is also intriguing for me in middle age is the realization that I am not so substantially different from the adolescent I was a long time ago. I still want to change the world, and I still get into trouble with people who like the world the way it is, or, at least, do not want to expend any energy in transforming what they frequently assume cannot be changed anyway. The story frames a little of experience, and invites me to ponder the rendition of events presented here, as well as to challenge this rendition and consider other alternative versions. Above all, I am compelled to ask what the woman I 
have pseudonymously named Cassandra remembers, if anything, about this incident, and to ask how this story might be transformed if it were told in a prose narrative, or as an incident in a film, or written in light in a photograph, or told with an accompanying soundtrack of Bach or Procol Harum.

As Ondaatje (2002) understands: "In writing, especially in poetry, you are always trying to find ways to forge alliances between unlikely things, striking juxtapositions, finding the right shorthand for ideas, metaphors" (34). I agree with Ondaatje's observation that the writer is always "trying to find the right balance for the emerging organic form" (136). Ultimately this is the goal of narrative inquiry, too. While attending to the experiences that comprise a story, and while seeking to understand the interpretive significance of narrative, the narrative researcher needs to attend to the discourse of narration, even perhaps operating with the conception of narration, not as a noun, something solid and fixed, but as a verb, narrating, always in process, full of generative action. To foster narrative inquiry as a verb requires constant vigilance regarding how the story is told, and how the story might be told, sustaining a creative connection with the plural possibilities of any narrating.

\section{References}

Amis, M. (2000). Experience. New York: Hyperion.

Arnason, D. (1992). A girl's story. In G. Bowering \& L. Hutcheon (Eds.), Likely stories: A postmodern sampler (pp. 4-18). Toronto: Coach House Press. Baldwin, C. (2005). Storycatcher: Making sense of our lives through the power and practice of story. Novato: New World Library. 
Bruner, J. (1987). Life as narrative. Social Research, 54(1), 11-32.

Chatman, S. (1978). Story and discourse: Narrative structure in fiction and film. Ithaca: Cornell University Press.

Clandinin, D. J. \& Connelly, F. M. (2000). Narrative inquiry: Experience and story in qualitative research. San Francisco: Jossey-Bass.

Cobley, P. (2001). Narrative. London: Routledge.

Creech, S. (2001). Love that dog. New York: HarperCollins.

Freire, P. (1993). Pedagogy of the city. New York: Continuum.

Fulford, R. (1999). The triumph of narrative: Storytelling in the age of mass culture. Toronto: Anansi.

Keefer, J. K. (1998). Honey and ashes: A story of family. Toronto: HarperCollins.

Marshall, B. K. (1992). Teaching the postmodern: Fiction and theory. New York: Routledge.

McHale, B. (1987). Postmodernist fiction. New York: Methuen.

Mills, S. (1997). Discourse. London: Routledge.

Ondaatje, M. (2002). The conversations: Walter Murch and the art of editing film. Toronto: Vintage Canada.

Walden, S. (2003). Places lost: In search of Newfoundland's resettled communities. Toronto: Lynx Images. 